\title{
Effectiveness of Ultrasound Therapy on Myofascial Pain Syndrome of the Upper Trapezius: Randomized, Single-Blind, Placebo-Controlled Study
}

\author{
Mustafa Aziz YILDIRIM(1), Kadriye ÖNEŞ@i), Gökşen GÖKŞENOĞLU®] \\ Department of Physical Medicine and Rehabilitation, \\ İstanbul Physical Medicine And Rehabilitation Training Research Hospital, İstanbul, Turkey
}

\begin{abstract}
Objectives: This study aims to evaluate the effectiveness of conventional ultrasound (US) therapy in the treatment of myofascial pain syndrome. Patients and methods: Fifty-four patients ( 23 males, 31 females; mean age $29.8 \pm 5.2$ years; range, 22 to 46 years) with myofascial pain syndrome were included in this prospective, randomized, single-blind, placebo-controlled study. Patients were randomized into two groups by computerized method as US group $(n=27)$ and placebo group $(n=27)$. Ten sessions of US were applied to the US group and 10 sessions of placebo US were applied to the placebo group. Treatment effectiveness was evaluated with Visual Analog Scale (VAS), algometer, palpable muscle spasm degree (PMSD), and Beck Depression Inventory (BDI) before and after treatment.

Results: Pain values after treatment in both groups decreased significantly $(p<0.05)$ compared to before treatment. In the US group, the decrease in VAS and palpable muscle degree before and after treatment was significantly higher $(p<0.05)$ than in the placebo group. In the US group, the decrease in PMSD after treatment was significantly higher than the placebo group $(p<0.05)$. The amount of decrease in BDI score before and after treatment in the US group did not differ significantly from the placebo group ( $p>0.05$ ).

Conclusion: Our findings show that conventional US therapy is effective in the treatment of myofascial pain syndrome.

Keywords: Myofascial pain syndrome; ultrasound; trigger point.
\end{abstract}

Myofascial pain syndrome (MPS) is a common cause of back and neck pain with painful taut bands, characterized by the presence of trigger points leading to motion restrictions, motor dysfunctions, and autonomic changes. Although its etiology is not fully understood, factors such as trauma, fatigue, excessive muscle tension, and structural disorders are considered.1,2 This syndrome may be the cause of pain alone, or it may be accompanied by other painful syndromes. In addition to pain, symptoms such as weakness and decreased range of joint movement may also occur. ${ }^{3}$ Trigger points are often seen in the upper trapezius muscle and cause pain attacks in about $85 \%$ of the population. ${ }^{4}$ The main objective in the treatment of MPS is to resolve the spasm, reduce the pain, and inactivate the trigger points. While spray and stretch techniques, ultrasound (US), transcutaneous electrical nerve stimulation, and heat packs are used as non-invasive treatments; dry needling, local anesthetics, and botulinum injections are the preferred invasive treatment methods. $^{5-7}$ US is a frequently used physical agent in soft tissue lesions, which increases

Received: June 20, 2017 Accepted: January 19, 2018 Published online: March 23, 2018

Correspondence: Mustafa Aziz Yıldırım, MD. İstanbul Fizik Tedavi Rehabilitasyon Eğitim ve Araştırma Hastanesi, Fiziksel Tıp ve Rehabilitasyon Kliniği, 34186 Bahçelievler, İstanbul, Turkey. Tel: +90 532 - 7127137 e-mail: m.yildirim20@saglik.gov.tr 
blood flow in tissues with its thermal effect, permeability in membranes, and tissue healing. It also reduces muscle spasms and increases the ability of collagen fibers to grow. In addition to the physiological effects and segmental analgesia with its non-thermal effects, it also has a micromassage effect which enables the movement of interstitial fluid in the tissues. ${ }^{8,9}$ Various investigations have been performed about the treatment of myofascial pain; however, there is still a lack of research on the most effective treatment strategies. Although some studies have demonstrated that US treatment for MPS considerably reduces pain intensity, current evidence is not clear enough to support US as an effective method to treat MPS. ${ }^{10-12}$ While there is no consensus on treatment, there are many treatment options for MPS. US therapy is a noninvasive, easily applicable, and also a controversial method in the literature. Therefore, in this study, we aimed to evaluate the effectiveness of conventional US therapy in the treatment of MPS.

\section{PATIENTS AND METHODS}

Fifty-four patients (23 males, 31 females; mean age $29.8 \pm 5.2$ years; range, 22 to 46 years) with MPS, who were admitted to the outpatient clinic between December 2009 and March 2010, were included in this prospective, randomized, singleblind, placebo-controlled study. Patients who had at least one trigger point in the trapezius muscle, neck and/or backache of less than six weeks and in normal range, and no sign of infection/ inflammatory findings in laboratory tests were included. Patients with cervical disc hernia, presence of radiculopathy or myelopathy, tumoral, infectious, psychiatric, systemic disease, stage 3-4 osteoarthritis, pregnancy, previous brain or shoulder surgery, treatment in the last six months, hormonal or rheumatic diseases were excluded. The study protocol was approved by the Istanbul Physical Medicine and Rehabilitation Education Research Hospital Ethics Committee. A written informed consent was obtained from each patient. The study was conducted in accordance with the principles of the Declaration of Helsinki.

Patients who satisfied the inclusion/exclusion criteria were randomly allocated to an US group $(n=27)$ or placebo group $(n=27)$ by using block randomization. A blind assessor evaluated all study parameter scales before and after treatment.

Patients in the US group were given $1 \mathrm{MHz}$ continuous conventional US treatment at a dose of 1.5 watts $/ \mathrm{cm}^{2}$ for five minutes with an US applicator with a $5 \mathrm{~cm}^{2}$ diameter of an Enraf Nonius (Sonopuls 490U, Rotterdam, The Netherlands) US device such that the trigger point is in the center and the device draws intertwining circles on and around the trigger point in one-two seconds. Patients in the placebo group were treated with the same method with placebo US treatment for 10 sessions every weekday while the US device was switched off. No analgesic drug was given to patients during this period. Stretching exercises and range of neck joint movement exercises were shown for upper and middle trapezius and pectoral muscles for all patients. Patients were advised to perform these exercises three times a day for 10 minutes. When they came for the treatment sessions, they performed the exercises under the doctor's supervision.

Trigger point pain was assessed with the following two criteria:

1) Visual analog scale (VAS): The scale used for the evaluation of pain included a $10 \mathrm{~cm}$ line drawn on a horizontal plane on a plain white paper with the words 'no pain' on one end and 'unbearable pain' on the other end. According to these explanations, patients were asked to mark their pain at rest and on movement on the $10-\mathrm{cm}$ line. Pain was assessed with VAS before and after the treatment. ${ }^{13}$

2) Algometry (dolorimeter): Pressure algometry is a semiquantitative method used to locate tender regions, abnormal sensitivity over muscles and bones, and assess pressure pain sensitivity of tissues. The measurements were performed three times with intervals of 60 seconds and the mean value was recorded as the pressure pain threshold. ${ }^{14}$ The severity of the palpable muscle spasm in the affected muscles was assessed on a scale of 0 to $4, i^{15}(0)$ no spasm, (1) medium-grade spasm, (2) spasm stronger than medium grade but not limiting range of joint movement, (3) severe spasm limiting range of joint movement, and (4) severe spasm accompanied by postural deviation.

Psychological status was assessed with the Turkish version of the Beck Depression Inventory (BDI). ${ }^{16} \mathrm{BDI}$ consists of 21 questions, and the 
Table 1. Demographic features of patients

\begin{tabular}{|c|c|c|c|c|c|}
\hline & \multicolumn{2}{|c|}{ Ultrasound Group $(\mathrm{n}=27)$} & \multicolumn{2}{|c|}{ Placebo Group $(n=27)$} & \multirow[b]{2}{*}{$p$} \\
\hline & $\mathrm{n}$ & Mean \pm SD & $\mathrm{n}$ & Mean \pm SD & \\
\hline Age (year) & & $29.8 \pm 5.2$ & & $31.1 \pm 5.7$ & 0.400 \\
\hline Body Mass Index $\left(\mathrm{kg} / \mathrm{m}^{2}\right)$ & & $23.7 \pm 3.2$ & & $24.5 \pm 3.2$ & 0.380 \\
\hline Sex & & & & & 0.409 \\
\hline Female & 17 & & 14 & & \\
\hline Male & 10 & & 13 & & \\
\hline Socioeconomic status & & & & & 1.000 \\
\hline Good-moderate & 25 & & 26 & & \\
\hline Poor & 2 & & 1 & & \\
\hline Education level & & & & & 0.362 \\
\hline Secondary-high school & 6 & & 9 & & \\
\hline College-University & 21 & & 18 & & \\
\hline Marital status & & & & & 0.402 \\
\hline Married & 12 & & 9 & & \\
\hline Single-widowed & 15 & & 18 & & \\
\hline Analgesic use & & & & & 0.551 \\
\hline Yes & 7 & & 9 & & \\
\hline No & 20 & & 18 & & \\
\hline
\end{tabular}

patients are asked to choose the answer best fitting their condition. Each question has four possible answers from a neutral condition ( 0 point) to the most severe condition (3 point). The highest possible score is 63 , with 0 to 13 points indicating no depression, 14 to 24 points indicating moderate depression, and scores higher than 25 points indicating severe depression.

Table 2. Comparison of pain at rest and during activity, algometer results, palpable muscle spasm degree, Beck Depression Inventory, and Short Form-36 scores between study groups before and after treatment

\begin{tabular}{|c|c|c|c|}
\hline & Ultrasound Group $(\mathrm{n}=27)$ & Placebo Group ( $n=27)$ & \\
\hline & Mean \pm SD & Mean \pm SD & $p$ \\
\hline \multicolumn{4}{|l|}{ Pain at rest (VAS) } \\
\hline Before treatment & $5.3 \pm 2.1$ & $5.3 \pm 2.2$ & 0.986 \\
\hline After treatment & $1.9 \pm 1.2$ & $3.7 \pm 1.8$ & $<0.001$ \\
\hline The difference before and after & $-3.4 \pm 1.5$ & $-1.6 \pm 0.9$ & $<0.001$ \\
\hline$p$ & $<0.001$ & 0.001 & \\
\hline \multicolumn{4}{|l|}{ Pain during activity (VAS) } \\
\hline Before treatment & $6.3 \pm 2.3$ & $6.4 \pm 2.2$ & 0.808 \\
\hline After treatment & $2.7 \pm 1.7$ & $4.5 \pm 1.9$ & 0.001 \\
\hline The difference before and after & $-3.6 \pm 1.8$ & $-1.9 \pm 1.2$ & $<0.001$ \\
\hline$p$ & $<0.001$ & $<0.001$ & \\
\hline \multicolumn{4}{|l|}{ Algometer results } \\
\hline Before treatment & $4.8 \pm 0.9$ & $4.6 \pm 0.6$ & 0.289 \\
\hline After treatment & $7.4 \pm 1.1$ & $5.4 \pm 0.7$ & $<0.001$ \\
\hline The difference before and after & $2.5 \pm 1.1$ & $0.7 \pm 0.5$ & $<0.001$ \\
\hline$p$ & $<0.001$ & $<0.001$ & \\
\hline \multicolumn{4}{|l|}{ Palpable muscle spasm degree } \\
\hline Before treatment & $1.1 \pm 0.8$ & $1.3 \pm 0.7$ & 0.393 \\
\hline After treatment & $0.6 \pm 0.6$ & $1.2 \pm 0.6$ & 0.001 \\
\hline The difference before and after & $-0.5 \pm 0.6$ & $-0.2 \pm 0.4$ & 0.009 \\
\hline$p$ & $<0.001$ & 0.046 & \\
\hline \multicolumn{4}{|l|}{ Beck Depression Inventory score } \\
\hline Before treatment & $11.0 \pm 8.2$ & $15.3 \pm 9.0$ & 0.075 \\
\hline After treatment & $8.7 \pm 6.8$ & $12.7 \pm 6.6$ & 0.035 \\
\hline The difference before and after & $-2.3 \pm 2.5$ & $-2.6 \pm 3.0$ & 0.696 \\
\hline$p$ & $<0.001$ & $<0.001$ & \\
\hline
\end{tabular}




\section{Statistical analysis}

Mean, standard deviation, median (min-max), ratio, and frequency values were used in the descriptive statistics of the data. The distribution of the variables was checked with the KolmogorovSmirnov test. Student's t-test or Mann-Whitney $\mathrm{U}$ test was used in the analysis of quantitative data, where appropriate. The Chi-squared test was used in the analysis of qualitative data, and the Fisher's exact test was used when the chi-squared test conditions could not be met. Paired samples t-test or Wilcoxon test was used for repeated measurements. IBM SPSS version 21.0 (IBM Corp., Armonk, NY, USA) statistical software was used in the analyses. A $p$ value $<0.05$ was accepted as statistically significant.

\section{RESULTS}

Mean age of the US and placebo groups was $29.8 \pm 5.2$ years and $31.1 \pm 5.7$ years, respectively $(p=0.400)$. There were no significant differences in age, weight, height and duration of pain, sex, marital status, economic status, education level or analgesic use between both groups ( $p>0.05$, Table 1).

Clinical comparisons of the groups were given in Table 2. There was no significant difference between US and placebo groups in terms of VAS (at rest), VAS (during activity), algometer, BDI, and palpable muscle spasm degree values before treatment ( $>00.05)$.

All clinical variables including VAS, algometer findings, palpable muscle spasm degree (PMSD) values and $\mathrm{BDI}$ scores improved with treatment in both groups (all $\mathrm{p}<0.05)$ when compared to baseline. The improvement percentages in VAS, $\mathrm{PMSD}$, and algometer values were higher in the US group than in the placebo group (all $p<0.05$ ) (Table 2). Only the improvement in the BDI scores did not differ between the groups ( $p>0.05)$.

\section{DISCUSSION}

In this placebo-controlled, single-blind study, we found that conventional US therapy is an effective treatment for MPS. Various methods are used for the inactivation of trigger points and relaxation of painful taut bands. US, a non-invasive treatment method, is a therapeutic agent commonly used due to its thermal and non-thermal effects. Similarly, in a study investigating US treatment used at the same dose (six minutes, 15 days) and frequency on the upper trapezius trigger points, a significant improvement was observed in pain and muscle spasms measured with the VAS and algometer. In addition, a slight increase was observed in the level of pain, spasms and depression at the third month control. ${ }^{17}$ Another randomized controlled study, in which US and placebo treatments were used for trigger points, did not show superiority of the combination of US, massage and exercise over the combination of massage and exercise and placebo US. This study stated that the reason for the difference between two groups was the difference in US dose used, and the combination of massage and exercise. ${ }^{18}$

In our study, analgesic and massage therapies were not applied while both groups were given stretching exercises in addition to US treatment. We think that combined treatment is effective in decreasing pain and palpable muscle spasms in both groups. In a study of 44 patients by Srbely et $a l .,{ }^{19}$ in which trigger point sensitivity and algometry were initially used, the first group was given US (1 watts/cm², $1 \mathrm{MHz}$, five minutes) and the second group was given placebo US; and the measurements immediately after 15 sessions of treatment found improved pain rates of $44.1 \%$ and $1.4 \%$, respectively. For MPS, there is no consensus regarding dose, frequency, duration, number of sessions in US therapy. In our study, we used continuous US therapy with 1.5 watts $/ \mathrm{cm}^{2}, 1 \mathrm{MHz}$, for five minutes and 10 sessions. In a study, Ilter et al. ${ }^{20}$ compared continuous US, pulsed US, and placebo US therapies using a frequency of 1 watts $/ \mathrm{cm}^{2}$ and $3 \mathrm{MHz}$ with continuous and pulsed US, and found that the effect of continuous US on pain was superior to pulsed and placebo US therapies.

Due to its thermal and non-thermal effects, US can be used for tissue repair, increasing the extensibility of collagen fibers, reducing pain and muscle spasms, as well as changing the permeability of ions through stable cavitation. The degree of these therapeutic activities varies depending on the touch absorbing property, the duration of application, the dosage, and the application scheme. ${ }^{21,22}$ Our patients were not 
given analgesic treatment or anti-depressants. In our study, no significant difference was established between the two groups while decreased BDI values were observed in both groups. Considering that chronic pain leads to depression, we think that depressive symptoms may decrease with pain relief. Based on the effectiveness of the compression and massage treatments applied at the trigger points, the state of well-being in the placebo group can be attributed to the effectiveness of the compression and massage of the US applicator. Massaging plays an important role in the treatment of pain. Massage treatment improves circulation, decreases pain and stress, increases relaxation, and helps general wellness of patients. ${ }^{23}$ Furthermore, the influence of intervention, stretching, and range of joint movement exercises and the presence of the patient in the treatment setting may be considered as other features that may increase the effectiveness of the placebo group.

Limitations of this study include the limited number of patients, the single-blind design, and the short-term follow-up period.

In conclusion, our study showed the effect of US, an important deep-heating agent, on pain, muscle spasms, and psychological state in the treatment of MPS. We think that US treatment can be used for trigger points as it is a non-invasive, painless, and easy to use method, suitable for patients avoiding injection therapy. However, we believe that a comprehensive approach including maintaining good posture with stretching and relaxation exercises and lifestyle changes is important in addition to medical treatment and physical therapy for long-term therapeutic efficiency. In future studies, it will be appropriate to examine different US parameters regarding dose, frequency, duration of treatment, and administration sites.

\section{Declaration of conflicting interests}

The authors declared no conflicts of interest with respect to the authorship and/or publication of this article.

\section{Funding}

The authors received no financial support for the research and/or authorship of this article.

\section{REFERENCES}

1. Raj PP, Paradise LA. Myofascial pain syndrome and its treatment in low back pain. Semin Pain Med 2004;2:167-74.

2. Jaeger B. Myofascial trigger point pain. Alpha Omegan 2013;106:14-22.

3. Hayden RJ, Louis DS, Doro C. Fibromyalgia and myofascial pain syndromes and the workers' compensation environment: an update. Clin Occup Environ Med 2006;5:455-69.

4. Dommerholt, J, Simons, David G. Myofascial pain syndrome-trigger points. J Musculoskeletal Pain 2008;16;211-28.

5. Simons DG, Travell JG, Simons LS. Travell and Simons' Myofascial Pain and Dysfunction: the Trigger Point Manual. Vol. 1, 2nd ed. Baltimore: Williams \& Wilkins; 1999.

6. Cummings TM, White AR. Needling therapies in the management of myofascial trigger point pain: a systematic review. Arch Phys Med Rehabil 2001;82:986-92.

7. Borg-Stein J, Simons DG. Focused review: myofascial pain. Arch Phys Med Rehabil 2002;83:40-7, S48-9.

8. Speed CA. Therapeutic ultrasound in soft tissue lesions. Rheumatology (Oxford) 2001;40:1331-6.

9. Gonçalves MC, Teixeira da Silva EG, Chaves TC, Dach. F, Speciali JG. Static ultrasound and manual therapy in refractory migraine. Case report. Rev Dor. Sao Paulo 2012;13:80-4.

10. Koca I, Tutoglu A, Boyaci A, Ucar M, Yagiz E, Isik $\mathrm{M}$, et al. A comparison of the effectiveness of low-, moderate- and high-dose ultrasound therapy applied in the treatment of myofascial pain syndrome. Mod Rheumatol 2014;24:662-6.

11. Gur A, Koca I, Karagullu H, Altindag O, Madenci E. Comparison of the efficacy of ultrasound and extracorporeal shock wave therapies in patients with myofascial pain syndrome: A randomized controlled study. J Musculoskelet Pain 2013;21:210-6.

12. Xia P, Wang X, Lin Q, Cheng K, Li X. Effectiveness of ultrasound therapy for myofascial pain syndrome: a systematic review and meta-analysis. J Pain Res 2017;10:545-55.

13. Dixon JS, Bird HA. Reproducibility along a 10 $\mathrm{cm}$ vertical visual analogue scale. Ann Rheum Dis 1981;40:87-9.

14. Fischer AA. Documentation of myofascial trigger points. Arch Phys Med Rehabil 1988;69:286-91.

15. Hong CZ, Simons DG. Pathophysiologic and electrophysiologic mechanisms of myofascial trigger points. Arch Phys Med Rehabil 1998;79:863-72.

16. Tegin B. Turkish version of Beck Depression Inventory. Unpublished Doctorate Thesis 1980.

17. Kavadar G, Çağlar N, Özen Ş, Tütün Ş, Demircioğlu D. Efficacy of conventional ultrasound therapy on myofascial pain syndrome: a placebo controlled study. Agri 2015;27:190-6. 
18. Gam AN, Johannsen F. Ultrasound therapy in musculoskeletal disorders: a meta-analysis. Pain 1995;63:85-91.

19. Srbely JZ, Dickey JP. Randomized controlled study of the antinociceptive effect of ultrasound on trigger point sensitivity: novel applications in myofascial therapy? Clin Rehabil 2007;21:411-7.

20. Ilter L, Dilek B, Batmaz I, Ulu MA, Sariyildiz MA, Nas K, et al. Efficacy of Pulsed and Continuous Therapeutic Ultrasound in Myofascial Pain Syndrome: A Randomized Controlled Study. Am J Phys Med
Rehabil 2015;94:547-54.

21. Bertolini GRF, Karvat J, Kakihata CMM, Ribeiro LFC, Brancalhão RMC. Therapeutic ultrasound after sciatic nerve compression of Wistar rats. Neurol Res 2017;39:837-844.

22. Paliwal S, Mitragotri S. Therapeutic opportunities in biological responses of ultrasound. Ultrasonics 2008;48:271-8.

23. Imamura M, Furlan AD, Dryden T, Irvin E. Evidenceinformed management of chronic low back pain with massage. Spine J 2008;8:121-33. 